\title{
A Study on Social Assessment in Holistic Lifecycle Management
}

\author{
Fatih Karakoyun, Dimitris Kiritsis \\ Laboratory for Computer-Aided Design and Production, \\ School of Engineering, Swiss Federal Institute of Technology, Switzerland \\ \{fatih.karakoyun, dimitris.kiritsis\}@epfl.ch
}

\begin{abstract}
Sustainable manufacturing has been focus of the industry for some time. Due to the holistic nature of sustainability not only the manufacturing processes but the whole life cycle and the environmental, economic and social aspects of the product should be taken in to account. In order to leverage from the concept of sustainability it is necessary to involve it in decision making process in the supply chain. It is essential to have an evaluation procedure so as to involve it in decision making which should be capable of assessing economic, environmental and social performance of the product. Unfortunately the social dimension of sustainability is the least developed and even neglected because it is difficult to evaluate due to its quantitative and subjective nature. The social aspects of holistic life cycle approach will be presented in this paper.
\end{abstract}

Keywords: Sustainability assessment, holistic lifecycle management, S-LCA

\section{Introduction}

Several definitions of sustainability have been proposed, over time. The World Commission on Environment and Development declaration [6] reads: "sustainable development is a process of change in which the exploitation of resources, the direction of investments, the orientation of technological development, and institutional change are made consistent with the future as well as present needs"(Jovane et al. 2008).

There is now a well-recognized need for achieving overall sustainability in industrial activities, arising due to several established and emerging causes: diminishing non-renewable resources, stricter regulations related to environment and occupational safety/health, increasing consumer preference for environmentally-friendly products, etc. In particular, the manufacturing sector, which lies at the core of industrial economies, must be made sustainable in order to preserve the high standard of living achieved by industrialized societies and to enable developing societies to achieve the same standard of living sustainably (Jayal et al. 2010).

Sustainable manufacturing must respond to; economic challenges, by producing wealth and new services ensuring development and competitiveness through time; environmental challenges, by promoting minimal use of natural resources (in particu- 
lar non-renewable) and managing them in the best possible way while reducing environmental impact; social challenges, by promoting social development and improved quality of life through renewed quality of wealth and jobs (Jovane et al. 2008).

The problem of finding a balance between the economic, social, and environmental values of human development is now at the heart of the debate that involves men of culture, men of faith, economists and politicians, who are working together to tackle the problems of globalization. At the center is a reflection of the responsibilities of politics and economics that is related to the imbalance of the world's social and economic order, putting in danger the ultimate goal for a civil society which is to guarantee an acceptable human condition that may be 'shared', starting from the common membership of a network of international relationship that is central to our age (Pepe 2007).

In the last few decades, ethics in business activities has become part of the wider concept of CSR, which is developing from a good idea to a critical part of business activity. CSR has become important in terms of consumers' perceptions, so it has become important for all consumer-oriented firms. Corporate social responsibility (CSR) is a broader concept and not limited to supply chains, but to the companies' overall treatment of human beings and the environment. Broadly speaking, the construct of CSR as we know it today has two main characteristics. Firstly, it describes the relationship between business and the larger society. Secondly, it refers to a company's voluntary activities in the area of environmental and social issues (Andersen \& Skjoett-Larsen 2009).

Usually, studies of supply chain management have concentrated on economic issues, such as finding ways to minimize the operational costs or to maximize profits. Sustainable supply chain management (SSCM) may be defined as the strategic, transparent integration and achievement of an organization's social, environmental, and economic goals in the systemic coordination of key inter-organizational business processes for improving the long-term economic performance of an individual company and its supply chain (Carter \& Rogers 2008).

All over the world, companies make business decisions every day which affect people and environment, directly through their own operations, or indirectly through the value chain of their business. Increasingly, these companies are confronted with questions, e.g. from customers, consumer organisations and other NGOs, regarding their social performance. Society's expectations to companies to assume a wider responsibility for the social impacts of their business activities is a challenge that has been accepted by companies that wish to conduct business in a more responsible way. Many companies, thus, see themselves in need of a tool which can help them make informed decisions about their social impacts throughout the life cycle of their products (Dreyer et al. 2005).

Holistic life cycle approach is an evaluation methodology which takes into account the whole life cycle of a product and generates performance characteristics (technical, environmental, economic and social) of a product or product system. The life cycle data is collected from all the actors of value chain and transformed into performance characteristics, which may further be used for decision making. The social aspects of the evaluation procedure are presented in this paper. 


\section{State of the art (Social life cycle assessment)}

Social sustainability sees the development of society as a way of ensuring the participation of all members of society. This involves creating a balance between social forces with a view to achieving a livable society that is sustainable in the long term. As regards training, this means, for example, offering equal opportunities when it comes to accessing learning content irrespective of the geographical location of individual members of society. Manufacturing processes in mass production require workers who have an elementary education and need additional customized training programs that are independent of specific manufacturers and products (Marxer et al. 2011).

The technical system produces many effects (positive and negative) upon human well-being, which are experienced as social impacts by stakeholders (for instance, workers, consumers, local society, etc.) involved in the life cycle. Assigning these effects to one functional unit highlights the balance between the advantages (the units of service provided) and often the drawbacks (for example, quantities of health destroyed).

Social impact refers to consequences caused by activities corresponding to various stakeholders. As far as social impacts are concerned, the consequences may be derived from three dimensions: behaviors (specific behavior/ decision) social-economic processes (the socio- economic decision e.g. investment decision) and capitals (human, social, cultural context) (Sanchez Ramirez \& Petti 2011).

When referring to the causes of social impacts, this generally implies three dimensions behaviors (social impacts are those caused by a specific behavior), socioeconomic processes (social impacts are the downstream effect of socio-economic decisions), and capitals (social impacts relate to the original context (attributes possessed by an individual, a group, a society e.g., education level) (Benoît 2010).

Those three dimensions are not exclusive and have dynamic relationships: socioeconomic processes have effects on behavior that may also be rooted in the attributes possessed by an individual or a group. Since the social impacts are often perceived as being very complex and subjective, it is not recommended to define attributes of relationships unilaterally and from there define a set of related indicators isolated from the stakeholder context. As for environmental impacts (cf. the doubts expressed by the non-believers of human-induced climate change), defining social impact categories needs to go through a subjective and inter-subjective process, preferably at the international level (Benoît 2010).

The methods available for working with social aspects in the supply chain include stand-alone tools as well as guidelines and standards. The difference between tools and standards are not clear-cut, and either or could be used as point of departure for improved social performance. The most established method is social impact assessment, but as the focus on social impacts within business (and within society at large) has increased over the last few years, so has the number of methods for assessing, reporting and improving performance with regard to these impacts. The most important methods are; Social Impact Assessment, Social Accountability 8000 Standard, 
The Global Reporting Initiative, UN Global Compact, Social Life Cycle Assessment of Products, ISO 26000: Guidance for social responsibility (Palme 2011).

A social and socio-economic Life Cycle Assessment (S-LCA) is a social impact (and potential impact) assessment technique that aims to assess the social and socioeconomic aspects of products and their potential positive and negative impacts along their life cycle. It is stated that: 'The ultimate objective for conducting an SLCA is to promote improvement of social conditions and of the overall socio- economic performance of a product throughout its life cycle for all of its stakeholders'. Thus, according to this statement, SLCA should be developed in such a way that its use in some way creates a more socially beneficial situation for the stakeholders in the product life cycle (Jørgensen et al. 2012).

S-LCA allows increasing knowledge, providing information for decision makers and promoting improvement of social conditions in product life cycles (Benoit et al., 2010). S-LCA helps inform incremental improvements but does not in itself provide a breakthrough solution for sustainable consumption and sustainable living. Those topics go well beyond the scope of the tool. S-LCA provides information on social and socio-economic aspects for decision making, instigating dialogue on the social and socio-economic aspects of production and consumption, in the prospect to improve performance of organizations and ultimately the well-being of stakeholders (Benoît 2010).

One important feature to be emphasized is that social impact is not directly linked to the production chain process of a product, it is not determined by physical flows, unlike the E-LCA, but from the way it interacts with the stakeholders. Therefore, the identification of all stakeholders involved on the product/service life cycle is a fundamental issue when performing an S-LCA (Sanchez Ramirez \& Petti 2011).

\section{Social Evaluation in Holistic life cycle approach}

Holistic life cycle approach is a product evaluation procedure, which takes into account the whole life cycle of the product (material extraction, production, use and disposal) and provides performance characteristics (technical, environmental, economic and social) in order to have a broad perspective about the all activities of the product and processes. HLA may provide valuable information in order to be used in decision making and reduces the risk of decision making.

LCA, LCC and S-LCA are combined in HLA. The methodologies involved in HLA have life cycle perspective thus avoids burden shifting. Since all the activities through the life cycle of the product is taken into account, their performances may be evaluated separately.

LCA and LCC is performed based on the unit processes concerning the product, however S-LCA is performed based on the interaction of the life cycle actors with the stakeholders around them. In order to combine LCA, LCC and S-LCA, the three methodologies should have the same system boundaries. The same LCI could be used for LCA and LCC, since the data needed for both methodologies are quantitative. LCI for S-LCA contains quantitative and qualitative data, and also data regarding to the 
stakeholders out of the value chain. A separate LCI should be prepared for S-LCA. Additionally, in some conditions the system boundaries for S-LCA should be extended in order to involve the missing stakeholders.

Social performance characteristics are evaluated by social life cycle assessment (SLCA). The guideline provided by UNEP are followed in S-LCA. Figure 1 illustrates the assessment framework for S-LCA.

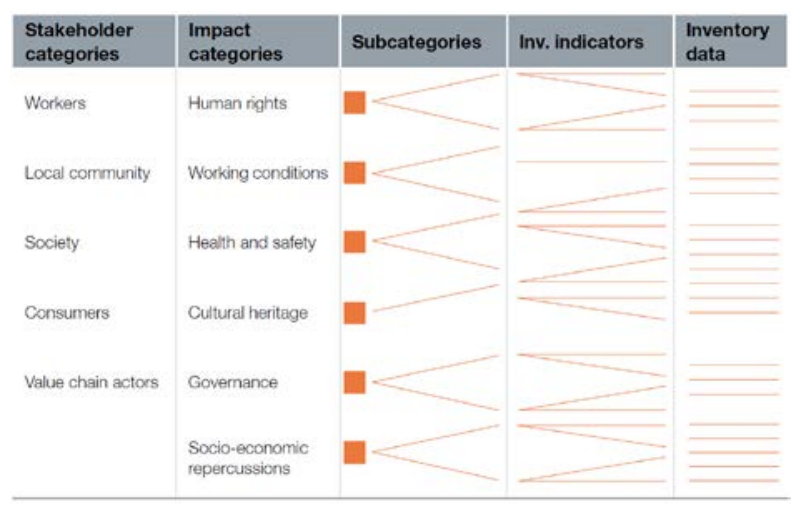

Figure 1 Assessment system from categories to unit of measurement

A stakeholder category is a cluster of stakeholders that are expected to have shared interests due to their similar relationship to the investigated product systems. Additional categories of stakeholders or further differentiations or subgroups can be added in order to have more detailed and precise subcategories of a specific stakeholder of concern may be identified (Benoît 2010). In spite the fact that, the environmental and economic aspects are related to the life cycle actor itself, social impacts may be occur in five main stakeholder categories presented in Figure 1, at each life cycle actors location. Additionally, it is necessary to note that the scope of S-LCA should be defined carefully because it will determine the number of companies that will be involved and contributed in the evaluation, and the amount of data that should be handled.

The aggregation of the sub categories is another issue since there will be qualitative and quantitative data will be collected during the study. This means the performance characteristics will also be both quantitative and qualitative.

\begin{tabular}{|c|c|c|c|c|c|}
\hline & & & Stakeholder & & \\
\hline & Worker & Consumer & Local community & Society & Value chain actors \\
\hline & Freedom of association & Health \& Safety & Access to material & Public commitments to & Fair competition \\
\hline & Child Labour & & $\begin{array}{l}\text { resources } \\
\text { Access to immaterial }\end{array}$ & Contribution to & Promoting social \\
\hline & Child Labour & Feedback Mechanism & resources & economic & responsibility \\
\hline 홍 & Fair Salary & Consumer Privacy & $\begin{array}{l}\text { Delocalization and } \\
\text { migration }\end{array}$ & $\begin{array}{l}\text { Prevention \& } \\
\text { mitigation }\end{array}$ & Supplier relationships \\
\hline 苋 & Working Hours & Transparency & Cultural Heritage & Technology developmen & $\begin{array}{l}\text { Respect of intellectual } \\
\text { property rights }\end{array}$ \\
\hline & Forced Labour & End of life responsibility & $\begin{array}{l}\text { Safe \& healthy living } \\
\text { conditions }\end{array}$ & Corruption & \\
\hline & Equal opportunities & & Respect of indigenous & & \\
\hline & /Discrimination & & rights & & \\
\hline & Health and Safety & & Community engagement & & \\
\hline & Social Benefits/Security & & Local employment & & \\
\hline & & & Secure living conditions & & \\
\hline
\end{tabular}

Figure 2 Subcategories for S-LCA 
Figure 2 shows the subcategories for S-LCA. The first think to do is to decide on the subcategories that will be included and excluded in the assessment and justify the decision. Second step is to collect inventory data concerning the sub categories. And finally, aggregate the data in a way that the alternative scenarios may be evaluated.

\section{Case Study (SUWAS)}

The SuWAS project (Sustainable Waste Management Strategy for Green Printing Industry Business) is an ECO-INNOVERA project aiming at the economic, social and environmental assessment of the deployment of a new technology at EU scale. This technology is patented and owned by the University of Alicante. The patent concerns the process to recover the waste-ink components of the (solvent-based) flexographic printing industry to generate secondary products. It is an alternative to the current costly (120 Euros/ton) mandatory incineration (hazardous waste). A general overview of the system under study is shown in Figure 3.

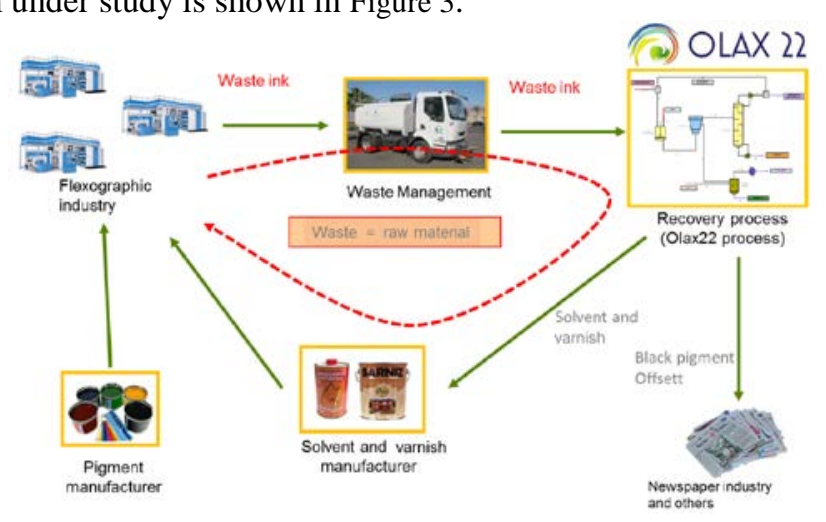

Figure 3 Overview of the system, with outputs

This study focuses on the end-of-life of waste-ink from the flexographic industry, including waste collection and treatment. This is a 'gate to grave' approach which does not consider the whole life cycle of the product (this would be a cradle to grave approach). The upstream life cycle stages of ink (production and use phases) have not been included into the study since; a) ink is considered as a waste, b) they are similar between the compared scenarios and would not provide any insights for the analysis.

The subcategories included in the social evaluation are shown in Table 1.

\begin{tabular}{|l|l|}
\hline - Worker & - Safe and healthy living conditions \\
- Fair salary $\mathrm{C}_{\mathrm{FS}}$ & - Local employment \\
- Working hours $\mathrm{C}_{\mathrm{WH}}$ & Society \\
- Health and safety $\mathrm{C}_{\mathrm{HS}}$ & - Public commitment to sustainability issues \\
- Consumer & - Tentribution to economic development \\
- Health and safety & Value chain actors \\
- Local of life responsibility & - Promoting social responsibility \\
- Access to material resources & \\
\hline - Delocalization and migration & \\
\hline
\end{tabular}

Table 1 Subcategories selected for SUWAS 
We cannot adhere to the system boundaries of the LCA and LCC study, because the recycling of the waste ink will reduce the need for imported ink from China. In this case, it is necessary to extend the system boundaries and include the ink production stage in the assessment.

Three scenarios were evaluated for processing waste ink; (1) it is incinerated in the waste disposal company, it is recycled in the printing facility, and it is recycled in the waste ink recycling company. These scenarios are evaluated in the region of UA in Spain, and EU level deployment of the process. Some of the performance characteristics for workers and the necessary information in order to evaluate them are shown in the table below.

\begin{tabular}{|c|c|c|c|}
\hline \multicolumn{2}{|c|}{ Performance Characteristics } & \multirow{2}{*}{$\begin{array}{l}\text { Required Data } \\
\text { Salary of the workers } \\
\text { Minimum living wage }\end{array}$} & \multirow[b]{2}{*}{$C_{F S}=\frac{\text { Salary of workers }}{\text { Min. living wage }}$} \\
\hline Fair salary & $\mathrm{C}_{\mathrm{FS}}$ & & \\
\hline Working hours & $\begin{array}{l}\mathrm{C}_{\mathrm{WH}} \\
\mathrm{C}_{\mathrm{OT}}\end{array}$ & $\begin{array}{l}\text { Weekly working hours } \\
\text { Authorized working hours } \\
\text { Overtime reported weekly }\end{array}$ & $\begin{array}{r}C_{W H}=\frac{\text { Weekly working hours }}{\text { Auth.working hours }} \\
C_{\text {or }}=\text { Weskly overtime reported }\end{array}$ \\
\hline The cost of man hour & $\mathrm{C}_{\mathrm{MH}}$ & $\begin{array}{l}\text { Salary of the workers } \\
\text { Weekly working hours }\end{array}$ & $C_{\text {MH }}=\frac{\text { Salary of the workers }}{\text { Monthly working hours }}$ \\
\hline Health and safety & $\mathrm{C}_{\mathrm{HS}}$ & $\begin{array}{l}\text { Number of incidents monthly } \\
\text { Avg. number of incidents in the sector }\end{array}$ & $C_{H S}=\frac{\text { Incidents reported monthly }}{\text { Average number of incidents }}$ \\
\hline
\end{tabular}

Table 2 Performance characteristics for workers

Comparison of the performance characteristics for three scenarios are illustrated in Figure 4. The workers in the second scenario have better conditions than the other scenarios, since they have better salary then the others, the working hours seem to be fair, and it offers a safer environment to work. However, it should be noted that the man/hour cost is higher in this scenario. In economic point of view, this scenario exhibits a higher labor cost, but the share of the labor cost among the other LCC items should be identified.

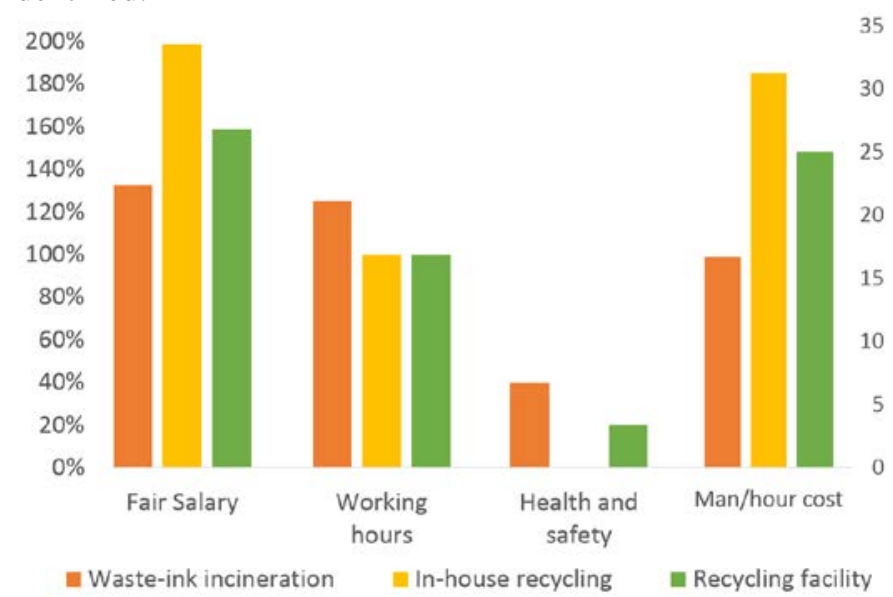

Figure 4 Comparison of performance characteristics for Workers 


\section{Conclusion}

Appraisal of sustainability requires a holistic approach that takes into account the whole life cycle of the product system and combination of a number of methodologies that evaluates the economic, environmental and social aspects of sustainability. Social sustainability which is one of the three pillars of sustainability, has been discarded not only because it is difficult to evaluate but also environmental and economic aspects have gained more attention in the last decade. Social-LCA aims to assess the social and socio-economic aspects of products and their potential positive and negative impacts along their life cycle in order to promote improvement of social conditions and overall socio-economic performance of a product for all its stakeholders. Stakeholders and subcategories should be determined carefully and elaborately so as to be able to evaluate the social performance of the product implicitly.

Acknowledgements. The authors would like to express our deep gratitude to all partners of SUWAS project and ECO-INNOVERA consortium.

\section{References}

Andersen, M. \& Skjoett-Larsen, T. (2009), Corporate social responsibility in global supply chains. Supply Chain Management: An International Journal, 14, pp.75-86.

Benoît, C. (2010). Guidelines for social life cycle assessment of products, UNEP.

Carter, C.R. \& Rogers, D.S. (2008), A framework of sustainable supply chain management: moving toward new theory, International Journal of Physical Distribution \& Logistics Management, 38(5), pp.360-387.

Dreyer, L., Hauschild, M. \& Schierbeck, J. (2005), A Framework for Social Life Cycle Impact Assessment, The International Journal of Life Cycle Assessment, 11(2), pp.88-97.

Jayal, A.D. et al. (2010), Sustainable manufacturing: Modeling and optimization challenges at the product, process and system levels, CIRP Journal of Manufacturing Science and Technology, 2(3), pp.144-152.

Jørgensen, A., Dreyer, L. \& Wangel, A. (2012), Addressing the effect of social life cycle assessments, The International Journal of Life Cycle Assessment, 17(6), pp.828-839.

Jovane, F. et al. (2008), The incoming global technological and industrial revolution towards competitive sustainable manufacturing, CIRP Annals - Manufacturing Technology, 57(2), pp.641-659.

Marxer, M., Keferstein, C.P. \& Weckenmann, A. (2011), Sustainable Manufacturing Using a Global Education Concept for Coordinate Metrology with a Blended Learning Approach, Advances in Sustainable Manufacturing SE-5, pp. 31-35.

Pepe, C. (2007). Corporate values in global supply chains. Symphonya, Emerging Issues in Management (www. unimib. it/symphonya).

Sanchez Ramirez, P.K. \& Petti, L. (2011), Social life cycle assessment: Methodological and implementation issues, The USV Annals of Economics and Public Administration, 11(1), pp.11-17. 